\title{
The diversity of blackberry habitus and its significance for cultivars' growing in the conditions of central Russia
}

\author{
Lidia Gruner*, and Boris Kornilov
}

Russian Research Institute of Fruit Crop Breeding (VNIISPK), 302530, Orel, Russian Federation

\begin{abstract}
The article deals with the main morphological groups of blackberries - erect, trailing and intermediates — semi-erect and semitrailing. The nature of shoots' growth and the way of natural vegetative reproduction were used as the basic criteria for this grouping, which together reflect the polymorphism of the plant being one of the adaptability indicators to different growth conditions. The expediency of such division for grouping of the existing blackberry cultivars' diversity with complex genetic origin was substantiated. As an additional criterion of this grouping, the shoots growth dynamics of morphological groups' typical representatives has been studied, which shows their differences during vegetation and in transition to period of plants' rest. In the phase of growth completion, the differences between group representatives were particularly clear: erect are characterized by early completion of growth processes, trailing do not finish them until the end of the growing season, semi-trailing/semi-erect complete growth in the term in between the first two groups. There is a difference in winter resistance of old erect cultivars and more modern members of this group of blackberries with different genetic origin; the latter's significant advantages are noted due to their thornlessness and lack of abundant growth. The role of plants' habitus of the main morphological groups' representatives for their cultivation in the conditions of the middle zone of Russia and, first of all, for overwintering cultivars; the value of both erect primocane-fruit cultivars and trailing - less winter-resistant, but the most convenient for winter shelter by habitus.
\end{abstract}

\section{Introduction}

In recent years, blackberries are actively distributed in amateur gardening of various regions of Russia, including in the auxiliary farms of the middle zone of our country. This is facilitated by the inflow of new foreign breeding cultivars of this culture to the domestic market, which have many valuable qualities: large fruits, harmonious taste, high yield, berries' transportability, relatively late ripening, which is important for the conveyor of vitamin horticulture products, thornlessness, resistance to diseases and pests, etc. The

\footnotetext{
*Corresponding author: gruner@vniispk.ru
} 
increased popularity of blackberries in the world over the past decades and the growth of its berry production are also reported by foreign researchers [1-3].

Despite the significant advantages of blackberries, the limiting factor in its cultivation in areas with cold winters and unstable snow cover remains insufficient winter resistance of most cultivars. This applies to the regions of the middle strip of Russia, which includes the Oryol region - the area of our research. Therefore, for successful cultivation of new foreign cultivars in these conditions and conducting effective breeding work on the creation of domestic cultivars, it is necessary to maximize the use of all adaptive capabilities of blackberry [4]. One of the adaptability indicators to different growth conditions is the morphological diversity characteristic of this culture $[5,6]$.

Among the morphological traits of blackberry, the natural plants' habitus associated with the type of shoots growth is the most important in determining the cultivation method and sometimes for the preliminary establishment of the cultivars' winter resistance level. Researchers usually distinguish 3 or 4 main morphological groups of this plant based on the nature of stem growth $[7,8$, etc.], and the method of natural vegetative reproduction $[7,9]$, namely: erect, trailing and intermediate between them - semi-erect and semi-trailing. Within each of these groups, there may be a different manifestation degree of these traits.

The frost resistance limit of most cultivars and species of blackberry created so far in the world is at the level of about $-10 \ldots-20^{\circ} \mathrm{C}$ [9-11, etc.]; winter temperatures in the Oryol region for a number of recent years $(2014 \ldots 2018)$ decreased in different periods to $-20 \ldots-31.5^{\circ} \mathrm{C}$ [12] with an absolute minimum of $-39,9^{\circ} \mathrm{C}$ (in 2012). Therefore, in order to preserve the plants themselves and the potential crop under these conditions, their mandatory early winter shelter is required. Natural plant habitus and the shoots growth patterns play an important role, especially when combined with a certain shaping pruning or other way of managing growth. In this regard, foreign researchers [13-15 et al.] have even developed a special cordon with a rotary mechanism - RCA, which allows to lay some cultivars' shoots on the ground by winter to shelter them, guiding the growing stems in a special way. A simpler way to preserve blackberry planting in winter, which does not require large labor and financial costs, is used by the authors of this article, being, in our opinion, the most convenient for evaluating inhomogeneous collection material [16]. It consists of the use of a low (up to $1.5 \mathrm{~m}$ ) flat cordon, on which 1-year stalks remain in winter and their shelter is made together with the cordon. Preliminarily, the shoots are formed by pruning or tied to the wires of the support structure, depending on the strength and nature of their growth. However, in the case of production plantings using several cultivars, other methods of cultivation and shelter may be applied considering certain habitus advantages of the selected cultivars. In this case, information on the shoots' growth nature is very important for cultivars' grouping and providing cultivar -specific agrotechnics.

Modern blackberry cultivars are complex hybrids created involving different cultivars and forms often having different natural habitus, which is transmitted to offspring in a certain way. Thus, when interbreeding cultivars with the same habitus, offspring with a similar shoots growth character are obtained, crossing erect and trailing types result in individuals of intermediate type [2]. At the same time, there are clear criteria by which representatives of different morphological groups can be distinguished from each other, but they are not always considered in practice and can lead to errors in cultivation technology, so we consider it important to focus on them in the materials of the article. These differences are noticeably manifested in older (from 3-4 years of age) blackberry plants at the end of the growing season when growth processes are finished.

The objective of this article is to show the most significant differences between the main morphological groups of blackberries, which can serve as reliable criteria for cultivars' grouping and the significance of these differences when growing blackberries in the middle zone of Russia. 


\section{Materials and Methods}

Objects of the study were collection cultivars' samples of blackberries placed in experimental plantings of the VNIISPK Department of Breeding and Variety Study of Berry Crops, of which typical representatives of studied morphological groups were chosen for research as model. In winter, plants were covered with white synthetic nonwoven fabric "agrotex" with $60 \mathrm{~g} / \mathrm{m}^{2}$ density in one layer. Plants were tied to 1.3-1.5 m high cordons leaving shoots tied to it for the winter as well. The research was carried out in accordance with the "Program and Methods of Variety Study..." [17]. The shoots growth dynamics of typical representatives of blackberries' main morphological groups was tracked by the average decade shoots growth of the current year based on the measurements of 10 shoots length for each sample in centimeters according to the specified method. The date of the growth accounting was the date of shoots' appearance above the ground level.

\section{Results and Discussion}

\subsection{Features of erect blackberries}

In VNIISPK genetic collection, typical representatives of the erect blackberries group are the old American cultivars Erie and Agawam, originating from the Eastern North American species Rubus argutus Link., Rubus allegheniensis Porter. and Rubus frondosus Bigel. [18]. They are characterized by intensive growth at the vegetation start with a peak of growth processes in the study region from mid-May to mid-June (Figure 1), which then completely end by early August and no longer resume, rarely responding to changing weather conditions. The stems grow vertically upwards or bend slightly arcuate near the apex. The natural vegetative reproduction way of such cultivars is the formation of root offspring, giving growth around the central plant by the 3-4 year of its life. These cultivars are characterized by early terms of flowering and berry ripening and have thorns.

\section{Erect blackberry shoots growth nature}

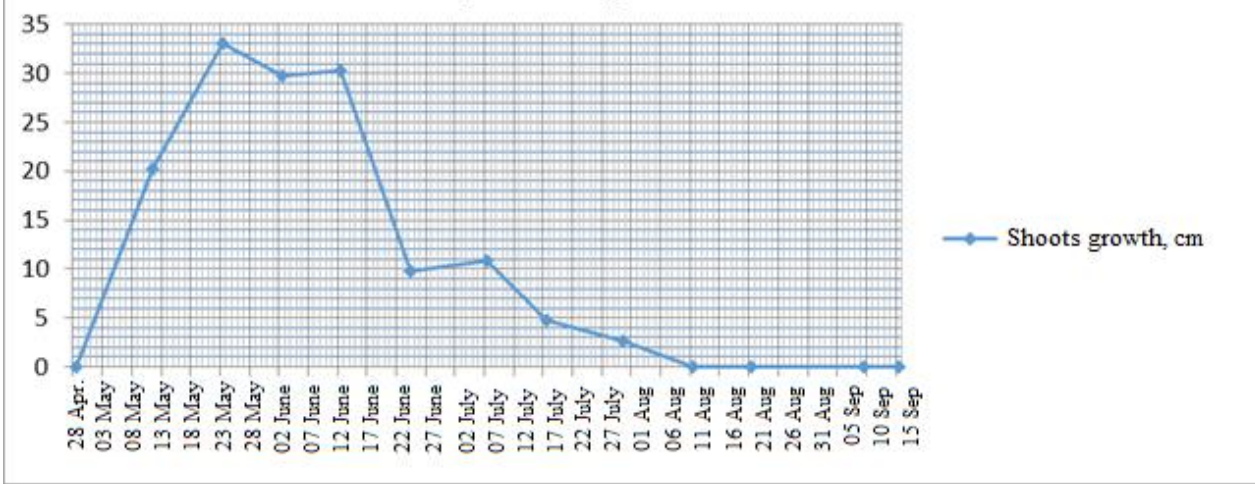

Fig. 1. Dynamics of shoots growth of Erie erect blackberry cultivar

When the growth is completed, apical buds are formed on the tops of the stems of the erect cultivars.

The listed morpho biological features of cultivars with erect shoots provide good ripening of their vegetative tissues and buds, which usually contributes to higher winter resistance compared to representatives of other groups. This has been repeatedly confirmed in Agawam 
cultivar, which has a wide cultivation range without winter shelter, including the area of our study [12].

Modern cultivars belonging to this group (Navaho, Arapaho, Apache, Ouachita, Osage, etc.) have a complex genetic origin [19-22, etc.] with the use of typically erect cultivars (Darrow, Cherokee, Hillquist, Brazos), as well as cultivars of trailing type, in particular, tetraploid $(2 n=4 x=28)$ sources of the recessive thornlessness gene $s$ (for example, cultivars Thornfree, Black Satin, etc.). As a result, the natural vegetative reproduction way of the obtained erect cultivars normally occurs in two ways - root offspring and annual shoots top rooting, which brings them closer to semi-erect (or semi-trailing) cultivars, which will be discussed further and which form a separate morphological group. Genetic similarity of modern representatives of these two groups is noted by the authors of cultivars [2, 23]. According to our preliminary data, in the conditions of central Russia these cultivars complete their growth later than typically erect cultivars - only by mid-September, which to a certain extent affects their winter resistance, reducing it compared to their erect predecessors. However, the great advantage of new cultivars over the old ones with similar habitus is a very small amount (or complete absence) of root-shoots resulting in zero clogging of the territory adjacent to the plants, as well as thornlessness of most of them, responsiveness to shaping.

A special place among the blackberry cultivars with erect shoots is occupied by the socalled primocane-fruit cultivars, which have been created relatively recently [2, 24, 25, etc.] and started to attract increasing attention of berry growers due to their ability to bear fruit on the shoots of the current year. This feature allows to obtain 2 harvests per year or one in autumn; after its ripening, the stems can be mowed off, thus solving the problem of winter resistance, winter shelter and resistance to diseases and pests. This is of special interest for cold regions, including the middle zone of our country. In addition, such cultivars can also be grown in areas with positive winter temperatures. However, the representatives of this group created so far produce a very late autumn harvest, which does not ripe in the conditions of the center of Russia, so they are grown either in a warmer climate or in special tunnels. In this regard, great hopes are placed on breeding studies aimed at increasing the early ripeness of such cultivars and greater frost resistance of the plants' underground part [2, 24, 26, etc.].

\subsection{Features of trailing blackberries}

A characteristic feature of cultivars and forms with trailing shoots is the intense prolonged growth of replacement shoots (Figure 2), which especially evident at the end of the growing season; it is responsive to changing temperatures and precipitation amount (each growth wave is usually associated with an increase in average daily temperatures or precipitation amounts) [27]. This growth continues in the area of our research until the onset of low (usually about $+10^{\circ} \mathrm{C}$ and below) autumn temperatures. At the same time, approximately from the beginning of September (and sometimes earlier), a rhizogenesis zone with reduced leaves is formed at the ends of annual shoots, which under favorable conditions (contact with soil) becomes the place of rooting and forming a side plant. As a rule, representatives of this group are much less frost-resistant than typically erect [9]. Therefore, they are mainly grown in regions with warm climate. However, the flexibility of their shoots is a valuable quality in bushes winter sheltering as they are easily laid on the ground or bend, and therefore can be used in more northerly zones. The high adaptability of blackberry forms with trailing shoots to the growth conditions is evidenced by the fact that this group is the most numerous in natural populations. Almost all wild species of blackberries growing on the territory of Russia have such habitus $[5,6]$.

There are a lot of acicular cultivars among the typically trailing cultivars having fruits with high taste qualities, such as Marion, Silvan, Karaka Black, Black Butte and others [8]. 
A great progress in the creation of cultivars with trailing shoots was the use of dominant thornlessness donors (with $\mathrm{S}_{\mathrm{f}}$ and $\mathrm{S}_{\mathrm{fl}}$ genes) - Austin Thornless $(2 \mathrm{n}=8 \mathrm{x}=56)$ and Lincoln Logan $(2 n=6 x=42)$ cultivars [2]. As a result, cultivars were obtained that release producers of a serious problem of thornness, which severely hampered the cultivation of blackberries. Cultivars with dominant thornlessness with $\mathrm{S}_{\mathrm{f}}$ gene - Waldo, Black Perl, Nightfall, Wild Treasure, etc. [28 et al.], c $\mathrm{S}_{\mathrm{fl}}$ gene - Columbia Star, Columbia Sunrise, Columbia Giant [29, 30 , etc.] - typically trailing with lying shoots and prolonged growth. Out of thornless group, cultivars with recessive thornlessness can also be attributed to trailing type (gene s) Thornfree, Loch Tay, Triple Crown, Black Satin and others, which are usually included in the semi-trailing cultivars' group [8, etc.] due to potent shoots and their vertical orientation at the initial growth stage of adult plants. However, prolonged growth at the end of vegetation, significant shoots length (up to $5 \mathrm{~m}$ or more) and natural reproduction usually only by apex rooting allow them to be attributed to the group in question.

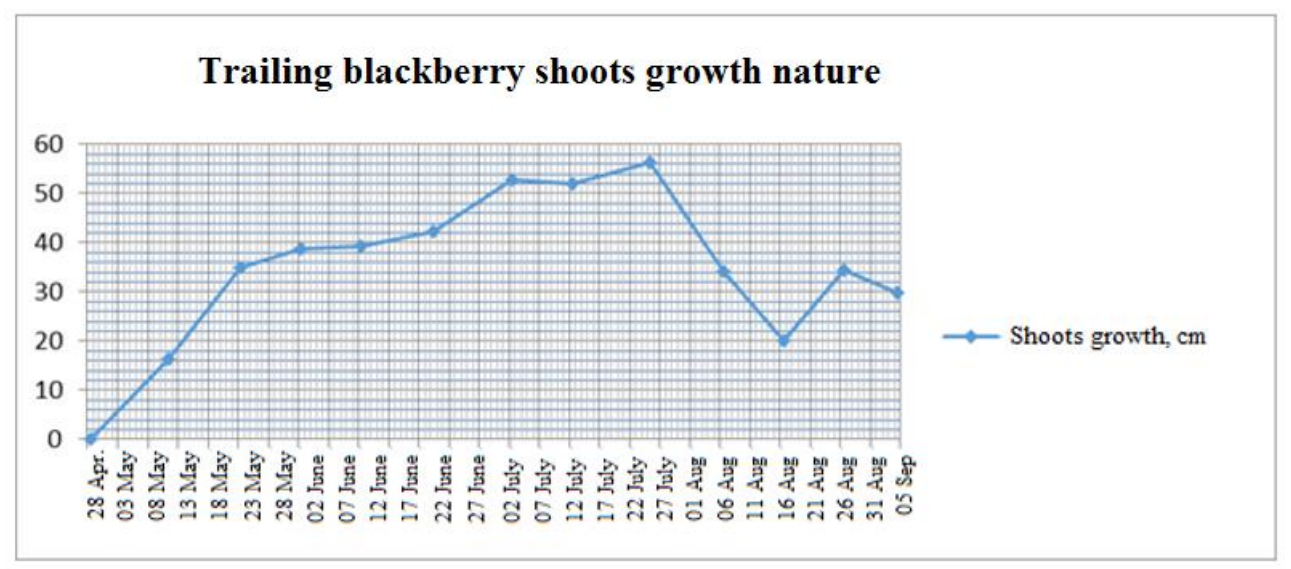

Fig. 2. Dynamics of shoots growth of Thornfree trailing blackberry cultivar.

\subsection{Features of semi-erect (semi-trailing) blackberries}

This morphological group includes cultivars and forms that have shoots growth character similar to trailing forms growth at the beginning and mid-vegetation, and at the end - with a completely interrupted shoots growth of erect forms, that is, the general nature of growth processes is intermediate type. However, usually such cultivars and forms end shoots growth in the area of our study by mid-September [27] (Figure 3) - much later than typically erect, forming shortened internodes and (or) an apical bud on the apex, while part of the shoots forms a rhizogenesis zone at the apex as in trailing forms. 


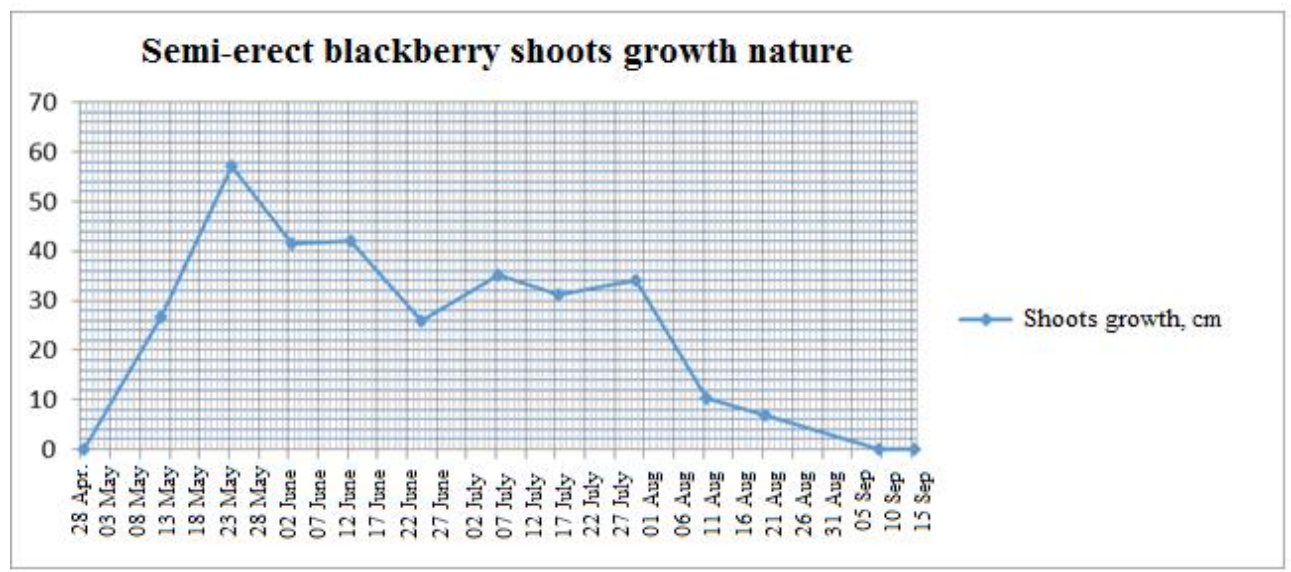

Fig. 3. Dynamics of shoots growth of semi-erect seedlings from open pollination of Black Satin cultivar

In this group, 2 subgroups can be distinguished: semi-erect and semi-trailing. Semi-erect predominantly multiply by root offspring, and the shoot apex rooting predominates in the semi-trailing, but in both cases the effectiveness of natural reproduction is much lower than that of typically trailing or typically erect. As a rule, winter resistance of cultivars and forms of this group is also of intermediate level in comparison with the plants of the first two groups, i.e. lower than in the erect and higher than that of the trailing, but in the end, this quality is determined by genotype. The group includes well-known cultivars - Brdzezina, Chester, Orkan, Cacanska Bestrna, Loch Ness, Natchez, Twiligh, Galaxy and a number of others [3133 etc.]. The nature of shoots growth of these cultivars eases their shaping ensuring high productivity of planting. At the same time, their stems are strong enough and convenient to keep the crop at the desired height. In the case of a winter shelter, it is difficult - and most often impossible - to lay adult plants of this type on the ground, so it is advisable to shelter the stems shaping them during the growing season tied to cordons. As mentioned above, modern cultivars of erect habitus are close to this group.

\section{Conclusion}

The main morphological groups of blackberries by the nature of growth and the method of natural vegetative reproduction are erect, trailing and semi-erect/semi-trailing. Differences between these groups are also identified at the end of vegetation at the completion of growth processes, the method of their vegetative reproduction is well identified at the same time: apex rooting or root offspring. Knowledge of these differences allows grouping cultivars for more successful use of cultivar technologies. When using a winter shelter in the conditions of the middle strip of Russia, various habitus cultivars are suitable with the most convenient being trailing and semi-trailing ones with flexible shoots. Old erect cultivars possess increased frost and winter resistance. By the nature of growth and the timing of its completion, most modern cultivars of erect habitus are close to the group of semi-trailing blackberries, which should be considered when growing them, but most of them are thornless, do not form root-shoots and are easily shaped. A special group of erect blackberries are primocane-fruit cultivars, which are fruiting on the shoots of the current year; they are promising in central Russia for being a non-covered culture when laying earlier autumn harvest. 


\section{References}

1. B.C. Strik, C.E. Finn, J.R. Clark \& P. Bañados, Acta Horticulturae, 777, 209-218 (2008) DOI: 10.17660/ActaHortic.2008.777.31

2. J.R. Clark, C.E. Finn, Global Science Books (Fruit, Vegetable and Cereal Science and Biotechnology), 5, 27-43 (2011)

3. URL:https://www.researchgate.net/publication/289212567_Blackberry_breeding_and_ genetics

4. B.C. Strik, C.E. Finn, Acta Horticulturae, 946, 341-347 (2012). DOI: 10.17660/ActaHortic.2012.946.56

5. L.A. Gruner, Contemporary horticulture, 3, 27-41 (2019). DOI:/10.24411/2312-67012019-10305.

6. S.V. Yuzepchuk, Flora of the USSR. M.-L., 8, 21-58 (1941)

7. A.A Grossgeim, Flora of the Caucasus. M.-L. 5, 44-58. (1952)

8. L.A. Gruner, Pomology, Orel, 5, 300-308 (2014).

9. C.E. Finn, B.C. Strik (2014). URL: http//berrygrape. org/ files/caneberries/ blackberry cultivars.

10. L.A. Gruner, In Proceedings Col. on applied Botany, Genetics and Breeding. L., 106, 85-86 (1986)

11. J. Wojcik-Seliga, E. Wojcik-Gront, Hort. Sci. (Prague), 40, 88-91 (2013)

12. Yu. Yu. Telepenko, Plant cultivars' studying and protection, 14(1), 124-131 (2018) DOI: 10.21498/2518-1017.14.1.2018.126521.

13. L. A. Gruner, O. V. Kuleshova, Contemporary horticulture, 2, 1-9 (2017), DOI: 10.24411/2218-5275-2017-00020.

14. F. Takeda, D. Handley, HortScience, 41(4), 1011 (2006). DOI: 10.21273/HORTSCI.41.4.1011D.

15. F. Takeda, D. Glenn and T. Tworkoski. Journal of Berry Research, 3, 25-40 (2013). DOI:10.3233/JBR-130044

16. D. Mettler, H. Hatterman-Valenti, Hort Science, 53(12), 1810-1813 (2018), DOI: 10.21273/HORTSCI13103-18

17. L.A. Gruner, S.D. Knyasev, O.V. Kuleshova. Bulletin of the Russian agricultural sciences, 4, 31-34 (2018) DOI: 10.30850/vrsn/2018/4/31-34.

18. I.V. Kazakov, L.A. Gruner, V.V. Kichina, Program and methods of varietal study of fruit, berry and nut crops Oryol, 374-395 (1999)

19. G.M. Darrow, Yearbook, 496-533 https://naldc.nal.usda.gov/download/IND43893570/PDF.

20. J.N. Moore, J.R. Clark, HortScience, 24 (5), 863-865 (1989)

21. J.N. Moore, J.R. Clark, HortScience, 8 (8), 861-862 (1993)

22. J.R. Clark, J.N. Moore, HortScience, 34 (7), 1291-1293 (1999) 22. J.R. Clark, J.N. Moore, HortScience, 40 (1), 258-260 (2005). DOI: 10.21273/HORTSCI.40.1.258

23. Ch.E. Finn, J.R. Clark, Fruit Breeding, 151-190. (2012). URL: https://link.springer.com/content/pdf/10.1007\%2F978-1-4419-0763-9_5.pdf

24. J.R. Clark, HortScience, 43(6), 1637-1639 (2008). DOI:10.21273/hortsci.43.6.1637

25. J. R. Clark, HortScience, 49(8), 1097-1101 (2014). DOI: 10.21273/HORTSCI.49.8.1097 
26. L.A. Gruner, B.B. Kornilov, Vavilov Journal of Genetics and Breeding, 24(5), 489-500 (2020) DOI: 10.18699/VJ20.641

27. L.A. Gruner, O.V. Kuleshova, Contemporary horticulture, 4, 42-49 (2014) URL: http://journal.vniispk.ru/pdf/2014/4/pdf. (In Russian. English abstract).

28. C.E. Finn, B.C. Strik, B. M., Yorgey, M. Qian, R.R. Martin, M.E. Peterson, HortScience, 45(3), 434-436 (2010) DOI: 10.21273/HORTSCI.45.3.434

29. C.E. Finn, B.C. Strik, B. M. Yorgey, M. E. Peterson, J. Lee, R. R. Martin, H. K. Hall, HortScience, 49(8), 1108-1112 (2014). DOI: 10.21273/HORTSCI.49.8.1108

30. C.E. Finn, B.C. Strik, B. M. Yorgey, M. E. Peterson, P. A. Jones, R. R. Martin, HortScience, 53(2), 256-260 (2018) DOI: https://doi.org/10.21273/HORTSCI1267317.

31. J.R. Clark, J.N. Moore, HortScience, 43 (6), 1897-1899 (2008). DOI: 10.21273/HORTSCI.43.6.1897

32. A. Orzeł, M. Simlat and J. Danek, Acta Horticulturae, 1133(1133), 29-34 (2016) DOI:10.17660/ActaHortic.2016.1133.5

33. C.E. Finn, B.C. Strik, B. M. Yorgey, M. E. Peterson, PA. Jones, J. Lee, N.V. Bassil R. R. Martin, HortScience, 55(6), 967-971 (2020). DOI: 10.21273/HORTSCI14985-20 